\title{
Nitrate reductase activity and oxalate content of sugar-beet leaves
}

\author{
F. van Egmond and H. Breteler \\ Department of Soils and Fertilizers, Agricultural University, Wageningen, \\ the Netherlands
}

Received: 20 March 1972

\section{Summary}

The nitrate and oxalate content of sugar-beet leaves increases with their ageing, when the plants are grown on nitrate medium.

The present research investigated the influence of high oxalate concentrations on the activity of nitrate reductase. The results showed that oxalate has no substantial effect on the activity of this enzyme.

\section{Introduction}

The metabolic conversion of nitrates into organic $\mathrm{N}$ gives rise to an equivalent quantity of carboxylates in plant tissues. Leaves of sugar-beet plants, grown on nitrate medium, accumulate considerable amounts of carboxylates, oxalate being the prevailing organic anion. Young leaves have a lower carboxylate and oxalate content than old leaves (van Egmond, 1971). In sugar-beet plants supplied with nitrate van Egmond and Houba (1970) observed a rapid decline in production of organic $\mathrm{N}$, expressed as the quantity of nitrate reduced per gram (dry matter) leaf blade per day. It was suggested that the steadily accumulating oxalate might cause a repression of nitrate metabolism. For this reason a further investigation was made of the effect of varying amounts of oxalate on the activity of the enzyme nitrate reductase (reduced nicotinamide-adenine dinucleotide nitrate oxidoreductase E.C. 1.6.6.1.).

\section{Material and methods}

Diploid sugar-beet seeds were germinated in shallow dishes filled with sand moistened with demineralized water. After germination the equal sized seedlings were placed on a well-aerated nutrient solution. The composition of the nutrient solution was the same as used by van Egmond and Houba (1970), containing nitrogen as 6 meq $\mathrm{NO}_{3} / 1$. The nutrient solution was renewed at regular intervals in order to avoid possible nutrient shortages. The plants were grown in a growth chamber. The daily light period was 14 hours, while the temperature was $25^{\circ} \mathrm{C}$ during the light period, and $17^{\circ} \mathrm{C}$ during the dark period. The relative humidity of the air was $70 \%$. The experiments were carried out with plants 4 and 8 weeks old. To determine the enzyme activity, organic anions, total nitrogen and nitrate, samples were taken from comparable leaves of different plants. 
A part of a fresh leaf sample was analysed for nitrate reductase activity (NRA), the remainder of the leaf material was dried at $70^{\circ} \mathrm{C}$ for 24 hours. The dried material was finely ground and analysed for organic anions, nitrate and total nitrogen as described by Houba et al., (1971).

Determination of NRA: $2.00 \mathrm{~g}$ of fresh leaf material were cut into small pieces with scissors, and homogenized together with $25 \mathrm{ml}$ of extraction solution. This extraction solution, a sucrose-cysteine-phosphate buffer of pH 7.5, consisted of 1 litre $0.1 \mathrm{M}$ phosphate $\left(0.08 M \mathrm{Na}_{2} \mathrm{HPO}_{4}+0.02 M \mathrm{KH}_{2} \mathrm{PO}_{4}\right)$ and $0.5 M$ sucrose $+100 \mathrm{ml} 0.1 M$ cysteine $+10 \mathrm{ml} 0.003 M$ EDTA. For homogenization a cooled homogenizer was used for 30 seconds at $40,000 \mathrm{rev} / \mathrm{min}$. Care was taken to carry out all the preparatory work from weighing until incubation in a cold room at $1^{\circ} \mathrm{C}$. A 2-ml aliquot of the homogenate was incubated with $10 \mathrm{ml}$ reagent $(6 \mathrm{ml} 0.1 M$ phosphate buffer $\mathrm{pH} 7.5+3 \mathrm{ml}$ reduced NAD solution of $0.5 \mathrm{mg} / \mathrm{ml}+1 \mathrm{ml} 0.1 M \mathrm{KNO}_{3}$ ) in a centrifuge tube. The nitrate content in the leaf material used in these experiments was so high that omitting extra nitrate ions from the incubation solution had no effect on the amount of nitrite produced. Incubation continued for 30 minutes in a water bath at $30^{\circ} \mathrm{C}$. The reaction was stopped with $1 \mathrm{ml} 2 \mathrm{M} \mathrm{BaCl}_{2}$ and the precipitate centrifuged for 10 minutes at $17,000 \mathrm{~g}$. The supernatant was poured into a test tube and mixed with $5 \mathrm{ml} 1 \%(\mathrm{w} / \mathrm{v}$ in $2.5 \mathrm{~N} \mathrm{HCl})$ sulphanylamide and $5 \mathrm{ml} 0.02 \%(\mathrm{w} / \mathrm{v}) \mathrm{N}$-1-naphtylethylene diamine $\mathrm{HCl}$. After 30 minutes the optical density was measured with a Beckmann Model B spectrophotometer at $540 \mathrm{~nm}$. Standard series ( 0 to $30 \times 10^{-5} M \mathrm{NO}_{2}$ ) were prepared from $\mathrm{KNO}_{2}$. Extraction and assay conditions were in agreement with the conditions described by Sanderson and Cocking (1964), Bowerman and Goodman (1971) and Wallace and Pate (1965).

\section{Experimental}

Experiment I concerns the nitrate reductase activity (NRA) in leaves of varying age. Leaves of the same age (leaf number) were taken from 4-week-old sugar-beet plants and mixed to form one sample. NRA was determined in samples of the 6 oldest leaves the leaves younger than Leaf 6 were still unexpanded. Dried samples were analysed for carboxylates, nitrate and total nitrogen.

In Experiment II sampling and analysis were made in the same way, but 8 weeks old plants were used. There were 20 leaves per plant, of which about 14 were fully expanded. This leaf material was used in several experiments. The effect of oxalate on NRA was investigated in two ways: in Experiment IIIa fresh samples of young and old leaves were mixed in varying proportions, the mixed samples were homogenized and NRA was determined; in Experiment IIIb oxalate was added in increasing amounts, corresponding to $0,1000,2000,3000$ and 4000 meq oxalate per $\mathrm{kg}$ dry matter of the leaf, to a suspension with a relatively high NRA, prepared from leaves of average age. NRA was determined after adding the oxalate.

In Experiment IV, young and old leaves of 8-week-old plants were homogenized and the two homogenates were mixed in varying proportions. NRA was determined in the mixtures.

\section{Results and discussion}

The results of Experiment $I$ are given in Fig. 1. Note that when the leaf is older, it contains more nitrate and oxalate, and less organic N, while NRA is lower. A lower rate of nitrate reduction in small, unexpanded, young leaves compared with expanded young 


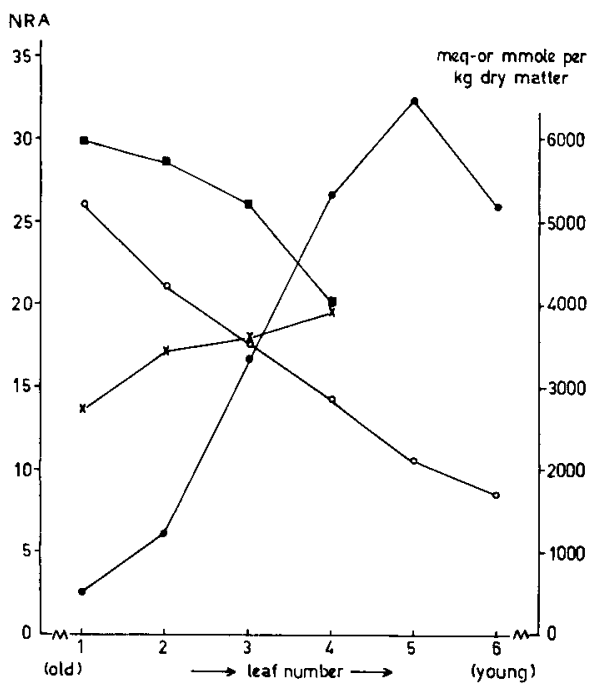

Fig. 1. Nitrate reductase activity, oxalate, organic $\mathbf{N}$ and nitrate content of leaves of different age. Experiment I: 4-week-old sugar-beet plants. Left hand ordinate: NRA ( $\mu \mathrm{mol} \mathrm{NO}_{2^{-}}$produced per gram leaf dry matter per hour). Right hand ordinate: $O$ oxalate; $x$ organic $N$; nitrate $(10 \times)$. meq or mmol per $\mathrm{kg} \mathrm{d.m.}$

leaves is also reported by Martin (1971) in bean plants and by Wallace and Pate (1965, $1967)$ in peas and cocklebur. Leaf 5 and Leaf 6 were not analysed for total nitrogen and nitrate, because no material was left.

It should be noticed that the fall in NRA with leaf age is relatively much greater than the decline of organic $\mathbf{N}$. This disproportionality means that the decline in NRA with age is not simply due to dilution of the nitrogenous substance in the leaf.

Nitrate reductase is known to be an adaptive enzyme, and if the pool of nitrate within the tissues is depleted, a fall in NRA may be expected. However Fig. 1 shows that all leaves had high nitrate contents, and the older leaves with low NRA contained more nitrate than the younger leaves with high NRA. From this it seems more likely that accumulation of nitrate is promoted by a low NRA.

Table 1 records the content of the various carboxylates in these sugar-beet leaves. From the apex to the base of the plant the carboxylate content of the leaves increases considerably, and oxalate is the prevailing carboxylate, especially in the old bottom leaves. These data and Fig. 1 show that increase in oxalate content and decrease in NRA occur simultaneously.

Table 1. Carboxylate content of leaves of different age in meq $/ \mathrm{kg}$ dry matter.

\begin{tabular}{llllllll}
\hline $\begin{array}{l}\text { Leaf } \\
\text { number }\end{array}$ & Fumarate & Succinate & Malonate & Oxalate & Malate & Citrate & Sum carboxylates \\
1 old & 40 & 16 & 44 & 5236 & 76 & 424 & 5836 \\
2 & 56 & 32 & 52 & 4220 & 92 & 496 & 4989 \\
3 & 56 & 24 & 36 & 3552 & 52 & 384 & 4084 \\
4 & 40 & 64 & 28 & 2878 & 76 & 384 & 3554 \\
5 & 72 & 32 & 28 & 2128 & 124 & 296 & 2680 \\
6 young & 64 & 40 & 40 & 1744 & 124 & 300 & 2312 \\
\hline
\end{tabular}




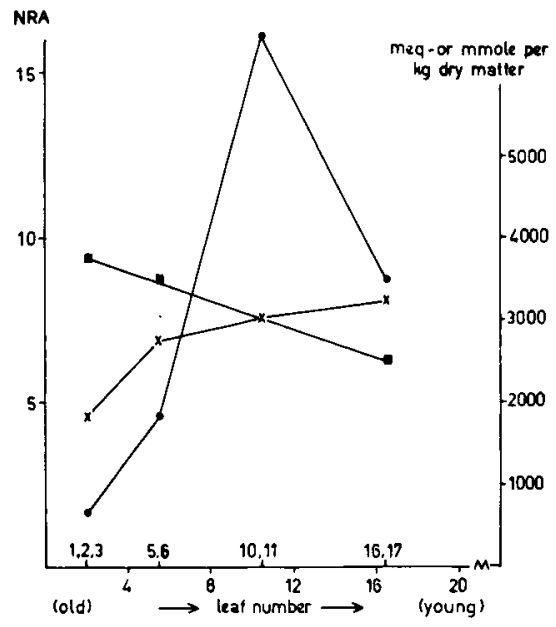

Fig. 2. Nitrate reductase activity, organic $\mathbf{N}$ and nitrate content of leaves of different age. Experiment II: 8-week-old sugar-beet plants. Left hand ordinate: NRA $\left(~\left(\iota \mathrm{mol} \mathrm{NO}_{2}{ }^{-}\right.\right.$produced per gram leaf dry matter per hour). Right hand ordinate: $\mathbf{x}$ organic $\mathbf{N}$; nitrate $(5 \times)$; meq or mmol per $\mathrm{kg}$ d.m.

The results of Experiment II are summarized in Fig. 2. Although obtained with older plants, the results are similar to those of Experiment I. Again, a drop in NRA is observed when passing from the expanded leaves to the still unexpanded leaves.

Fig. 3 shows the results of NRA determinations on homogenates of mixtures of young and old leaves, as determined in Experiment IIIa. The broken line is calculated from NRA in the unmixed leaf samples of Experiment II and their proportion in the mixture, as the two samples differed in dry matter content the line curves. It is seen that the values of NRA determined in the mixtures are higher than the calculated ones. Since the leaves are large, and the enzyme may not be equally distributed over the leaf, sampling errors may be involved. In Experiment IV this error is avoided.

In Experiment IIIb a homogenate of high NRA was incubated after adding various amounts of potassium oxalate. Fig. 4 shows that NRA fell to some extent, but very little compared with the decline of NRA with leaf age (compare Fig. 2). The leaves used for

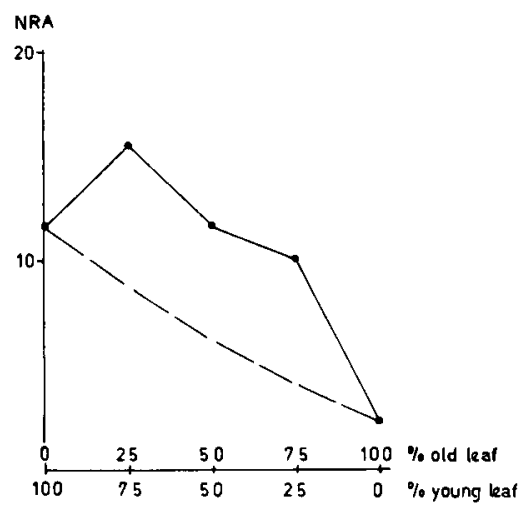

196
Fig. 3. Nitrate reductase activity ( $u$ mol $\mathrm{NO}_{2}$ - produced per gram leaf dry matter per hour) of mixtures of young and old sugar-beet leaves. Experiment III: 8week-old plants. 

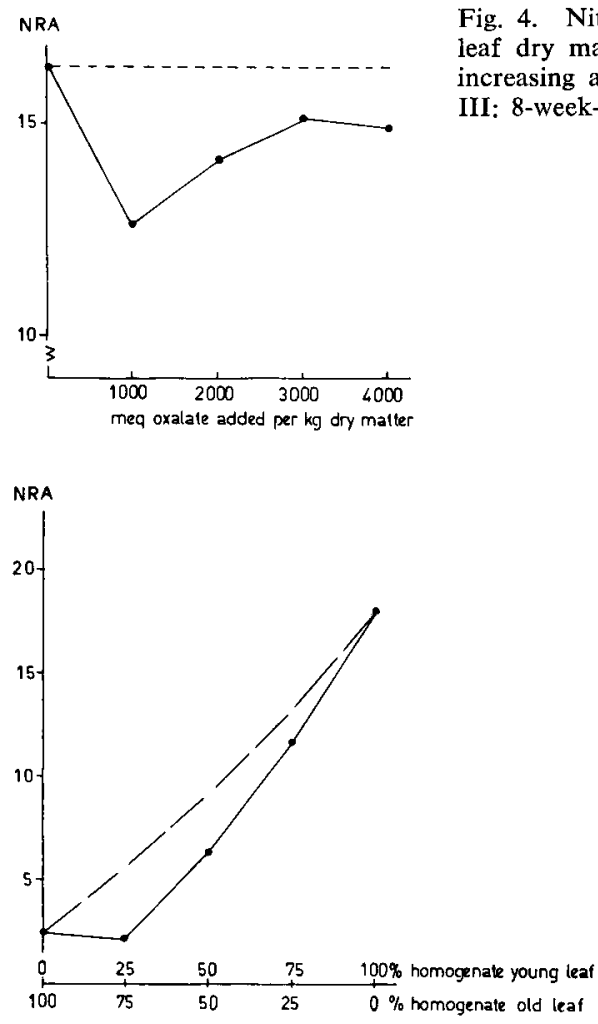

Fig. 4. Nitrate reductase activity ( $\mu \mathrm{mol} \mathrm{NO}_{2}^{-}$produced per gram leaf dry matter per hour) of a sugar-beet leaf after addition of increasing amounts of oxalate during the incubation. Experiment III: 8-week-old plants.
Fig. 5. Nitarte reductase activity $\left(\mu \mathrm{mol} \mathrm{NO}_{2}^{-}\right.$produced per gram leaf dry matter per hour) of mixtures of homogenates of old and young leaves. Experiment IV: 8-week-old plants.

the homogenate contained about 2000 meq oxalate $/ \mathrm{kg}$ dry matter so that the maximum addition of potassium oxalate raised the actual oxalate concentration to a value comparable with $6000 \mathrm{meq}$ oxalate/ $\mathrm{kg}$ dry matter in the leaf. Such a high level of oxalate occurs in the matured bottom leaves of very low NRA, but the addition of extra oxalate had little effect on NRA of the homogenate. From this it follows that the increase in oxalate concentration associated with natural ageing of the leaf does not interfere with the activity of nitrate reductase within the leaf. This is confirmed by the results of Experiment IV given in Fig. 5. Fig. 5 shows that the mixtures of homogenates prepared from young and old leaves respectively had nitrate reductase activities which differed only little from the values calculated from the NRA's of the original homogenates and their proportion in the mixture, as represented by the broken line.

\section{Conclusion}

Although a decrease in NRA in sugar-beet leaves occurs simultaneously with an increase in oxalate content of these leaves, the present experiments prove that oxalate as such does not cause a NRA decrease in vitro. 


\section{Acknowledgment}

We wish to thank Ir A. Darwinkel for his advices on the NRA determination, Mr E. M. Wittich for analytical assistance, and Dr A. C. Schuffelen for critical reading of the text.

\section{References}

Bowerman, A. \& P. J. Goodman, 1971. Variation in nitrate reductase activity in Lolium. Ann. Bot. 35: $353-366$.

Egmond, F. van, 1971. Inorganic cations and carboxylates in young sugar-beet plants. Colloquim on 'Potassium in biochemistry and physiology'. International Potash Institute, Uppsala, June 1971.

Egmond, F. van \& V. J. G. Houba, 1970. Production of carboxylates (C-A) by young sugar-beet plants grown in nutrient solution. Neth. J. Agric. Sci. 18: 182-187.

Houba, V. J. G., F. van Egmond \& E. M. Wittich, 1971. Changes in production of organic nitrogen and carboxylates (C-A) in young sugar-beet plants grown in nutrient solutions of different nitrogen composition. Neth. J. Agric. Sci. 19: 39-47.

Martin. P., 1971. Reduktion von ${ }^{15} \mathrm{NO}_{3}$-Stickstoff und Einbau in das Eiweisz in verschieden alten Blättern von Buschbohnenpflanzen. Z. Pfl.Ernähr. Bodenk. 128: 143-153.

Sanderson, G. W. and E. C. Cocking, 1964. Enzymic assimilation of nitrate in tomato plants. I. Reduction of nitrate to nitrite. Pl. Physiol. 39: 416-422.

Wallace, W. \& J. S. Pate, 1965. Nitrate reductase in the field pea (Pisum arvense L.). Ann. Bot. 29 $655-671$.

Wallace, W. \& J. S. Pate, 1967. Nitrate assimilation in higher plants with special reference to the cocklebur (Xanthium pennsylvanicum Wallr.). Ann. Bot. 31: 213-228. 